\title{
A Study of Factors Influencing Chinese Students' Satisfaction toward Thai Universities
}

\author{
Paweena Songsathaphorn, Chenin Chen, and Athapol Ruangkanjanases, Member, IACSIT
}

\begin{abstract}
Given an intense competition in international education business these days, understanding the factors influencing Chinese students' satisfaction could facilitate Thai education providers and the government to improve and develop their programs to better satisfy potential Chinese customers in order to attract more Chinese students to Thailand. Therefore, the main objectives of this study were (1) to realize influential factors that have positive effect on Chinese students' satisfaction toward Thai higher education, (2) to examine level of Chinese students' satisfaction toward Thai higher education, and (3) to provide recommendations for both Thai higher education institutions and the government. This study is quantitative research using satisfaction questionnaire as a tool to collect primary data, from the sample size of $\mathbf{2 1 5}$ Chinese students studying in universities in Bangkok. Seven key factors were comprised and formulated as a conceptual model tested in this study. Data analysis and hypothesis testing were performed by using Pearson's product moment correlation and multiple regressions. The findings indicated that only four factors have significant positive influence on overall Chinese students' satisfaction toward Thai higher education. These four factors are education, safety, image and prestige of institution, and student's preparation before going abroad. The multiple regression models with these four factors could predict $60.8 \%$ of the variance in the overall student satisfaction.
\end{abstract}

Index Terms-Chinese, factors, influencing, satisfaction, Thai, universities.

\section{INTRODUCTION}

Rapid economic growth in Asia has been a main cause of the growth of trade in education as Asian countries have proved the importance of education in accelerating economic growth. Development continues to fuel Asia's demand for education. The demand for higher education will continue to grow. Governments across the region welcome trade in education intended for higher quality education and greater choice of studies.

In 2007, over 2.8 million students were enrolled in educational institutions outside of their country to origin. This represents 123,400 more students than in 2006, an increase of $4.6 \%$. The global number of mobile students has grown by $53 \%$ since 1999 (UNESCO Institute for Statistics, 2009). Asian countries' number of international students is expected to increase. Seeing that China and India alone may account for more than half of the total global demand for higher education by 2025 [1].

According to China's one-child policy, it has drastically

Manuscript received March 25, 2013; revised June 5, 2013.

The authors are with Chulalongkorn Business School, Chulalongkorn University, Thailand (e-mail: ms_paweena@hotmail.com, chenin.c@chula.ac.th, athapol@cbs.chula.ac.th). increased the spending power of the average household affording to pay for their children education. Sending a child to study abroad is a popular trend for Chinese families and the demand of Chinese students studying abroad has been consequently driven by rising incomes for their families.

In 2009, according to a survey conducted by Office of the Higher Education Commission [2], there were 19,052 international students, from 124 countries, studying in 103 Thai higher education institutions. The highest number of international students studying in Thailand was Chinese students with 8,993 students or $47.2 \%$ of the total.

As Chinese student is a majority and the main source of international students in Thailand, thus, it seems to be the most critical target group and is one of Thai's prominent export markets for education services.

International education industry is growing and having intense competition. In order to attract more potential Chinese students to come and study in Thailand, word-ofmouth or buzz marketing will pay an important role. Satisfying students will be good and effective advertisers for promoting Thai education for services. Thus, it is vital to recognize crucial factors that influence Chinese students' satisfaction toward Thai higher education.

\section{LITERATURE REVIEW}

\section{A. Student Satisfaction in Higher Education}

By referring to Elliott and Shin [3], they describe student satisfaction as "the favorability of a student's subjective evaluation of the various outcomes and experiences associated with education. Student satisfaction is being shaped continually by repeated experiences in campus life"

Student satisfaction can be seen as customer satisfaction. Today's rapid expansion of colleges and universities forces them to think differently about the role of student satisfaction for their continued existence. The focus on market-driven strategies in the international education has received considerable attention among universities all over the world. It requires not only to attract but also to retain students in this competitive environment [4]. Thus, they need to understand their target markets and modify their offerings to meet those needs.

There are many methods used to measure student satisfaction. As indicated by Kotler and Keller [5], periodic surveys can track their satisfaction directly and also ask the respondent's willingness to recommend the institution to others. Besides conducting periodic surveys, educational institutions can observe their customer loss rate or in this case the number of students enrolling or applying to the course. Dissatisfied students may cut down on the number 
of courses or drop out of colleges or universities completely.

Student satisfaction is not simply dependent on the teaching consideration only, but there should be an in-depth analysis to find out the whole influential factors that contribute to the student satisfaction. Measuring student satisfaction is not an easy task to attempt. Therefore, the critical factors or variables used to evaluate student satisfaction differ from one researcher to another.

\section{B. Student Satisfaction and Retention Model (SSRM)}

To measure student satisfaction, DeShields Jr, Kara and Kaynak [6] used a modified version of Keaveney and Young [7] Student Satisfaction and Retention Model, which consisted of a broad set of independent variables that in response was related to student satisfaction. They tested the model and focused on the links between faculty performance, advising staff performance, and classes and considered that these factors were the most important variables and critical in influencing students' experience with a college and university, which in turn impact on overall student satisfaction. It is known that satisfaction level is determined by the difference between the service performance as perceived by customer and what the customer expects [8]. Although, there are many variables that could influence students' perceived performance but the core services provided by institutions are normally instruction, and student advertisement. Thus, these three major factors were focused in [6].

The results of their study indicated that faculty performance (lecturer) and classes were key factors which had a significant influence on the student's college experience, and student's college experience was positively related to their satisfaction and intentions to stay at college or university. In addition, students who had a positive college experience were more satisfied with their college or university than students who did not have positive college experience.

\section{Herzberg's Two-Factor Theory}

Frederick Herzberg developed a two-factor theory that distinguishes two sets of factors: dissatisfiers or hygiene factors (factors that cause dissatisfaction) from satisfiers or motivators (factors that cause satisfaction). Satisfiers result in satisfaction when adequately fulfilled. Dissatisfiers cause dissatisfaction when undersupplied.

In reference to [6] applying Herzberg's theory to their study, faculty performance and classes were considered as satisfiers which directly related to student's college experience and their satisfaction. On the other hand, the performance of advising staff was considered as dissatisfier that may cause dissatisfaction. The absence of good advising staff performance may lead to dissatisfaction.

\section{Structural Equation Model of Student Satisfaction}

Based on the study of Arambewela and Hall [4] undertaking in Australia among four groups of international students from China, India, Indonesia, and Thailand. They tested and developed a model of student satisfaction and found that the importance of service quality factors related to both educational and non-educational services, which lastly impacted on student satisfaction. They used structural and equation model to analyze their collected data because it can deliberate overall test of model fit and represent a causal approach examining a set of relationships between independent variables and dependent variables. Seven factors were identified in their study: education, social, technology, economic, accommodation, safety, prestige and image, represented for both educational and non-educational issues that are perceived as important by the students from Asia in satisfaction formation. The results indicated that all factors were significant predictors of student satisfaction.

\section{E. Social Learning Theory}

In accordance with a research paper of Wang, Taplin and Brown [9], their study considered and used McLeod and Wainwright's social learning theory to assess mainland Chinese students' satisfaction of the study abroad program. Their study examined factors based on an individual's internal control or internal factor ("preparation") and those external factors faced in a study abroad program ("culture" and "technical teaching") which are beyond an individual's control. Their findings suggested that Chinese students' preparation before studying abroad is essential for the students to do well in the program and the students who felt they were better prepared for study abroad showed higher satisfaction. Therefore, preparation is the most significant factor in getting satisfaction out of the study abroad program.

\section{RESEARCH METHODOLOGY}

\section{A. Conceptual Framework}

The conceptual framework of this study was based on the literature review and related studies previously mentioned, which were used and modified in this regard to fit to the environment of the study. The researchers formulated a model comprising of one internal factor and six external factors, as independent variables, which were assumed to have an impact on student satisfaction. Chinese students' satisfaction was taken as a dependent variable. The model is exhibited in Fig. 1.

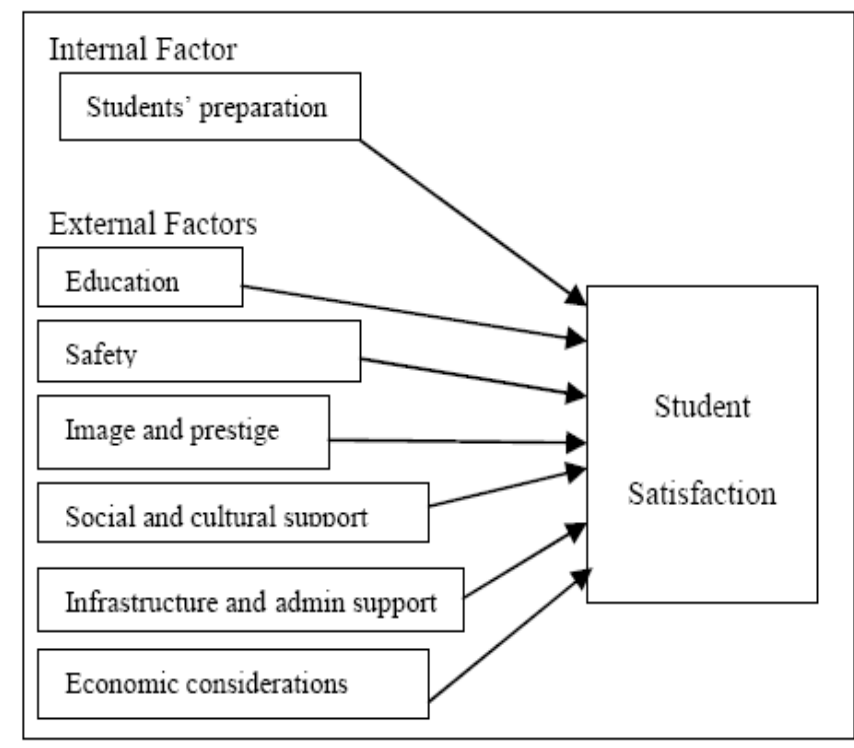

Fig. 1. Conceptual framework.

Based on the conceptual framework, hypotheses of this 
study were as follows:

- H1: All seven factors (student's preparation, student satisfaction with; education, social and cultural support, infrastructure and administrative support, economic considerations, safety, and image and prestige of institution) will have a positive relationship with overall student satisfaction.

- H2: All seven factors (student's preparation, education, social and cultural support, infrastructure and administrative support, economic considerations, safety, and image and prestige of institution) will be the significant predictors of overall student satisfaction.

\section{B. Data Collection}

A student satisfaction questionnaire, as a research instrument used in this study, was developed based on the literature review and related studies introduced earlier, and designed to achieve the objectives of the study. It was comprised of three parts; participants' personal information, Chinese students' satisfaction toward six external factors and their overall satisfaction rating, and comments and suggestions. According to Yamane [10], sample size of 255 questionnaires were handed out to mainland Chinese students studying at Thai higher education institutions, either public or private, in Bangkok at any level of their post-secondary study. A total of 215 completed questionnaires were obtained.

\section{Measures}

This study used a five-point Likert scale, ranging from Very Satisfied (5) to Very Unsatisfied (1), to measure Chinese students' satisfaction with six dimensions as well as their over satisfaction. The measurement of student satisfaction was done through a multi-item structure. First, the students had to rate levels of their satisfaction with Thai universities in each aspect and then ended off with their overall satisfaction. This approach can generate an accurate reflection on each factor critically considered as important to the overall student satisfaction. Based on the conceptual framework, the following constructs were used to measure level of Chinese students' satisfaction toward Thai higher education and tested the hypotheses of the study.

\section{Independent Variables}

The independent variables consisted of one internal factor; students' preparation before going abroad, and six external factors; education, social and cultural support, infrastructure and administrative support economic considerations, safety, and image and prestige of institution, which were hypothesized to have an impact on dependent variable.

In regard to students' preparation before going abroad, the questionnaire had 3 items under this factor. This issue measured how well Chinese students prepared themselves before studying in Thailand; preparation for communicating in English, for living, and for studying in Thailand. Education, a direct academic issue, the questionnaire had 10 items to measure students' satisfaction toward: education students receive (knowledge, skills, attitude), lecturer (assignments, communication and feedback, assessment), and class environment. In terms of social and cultural support, this factor concentrated on students' satisfaction with activities that help students minimize their culture shock from initial stage and any difficulties or pressure arising. The questionnaire had 3 items; counseling services, student orientation, and recreational activities. Infrastructure and administrative support was related to students' satisfaction with provided facilities and managerial support. The questionnaire had 8 items, for example; library resources, students visa application, computer, course registration, accommodation, and transportation. For Economic consideration, the questionnaire had 5 items which were referred to students' satisfaction toward: tuition fees, cost of living, financial aid, opportunity for part-time jobs as well as future migration. Safety was another concern; the questionnaire had 3 items which were referred to students' satisfaction toward: safe campus, no racial discrimination, and country positive image for safety. Image and prestige of institution was about students' satisfaction with university's reputation, which referred to; international reputation, reputation in student's home country (China) and also renown in Thailand. In addition, strength of the alumni connection can play a part in this factor. Under this factor, the questionnaire had 4 items to be measured.

\section{E. Dependent Variable}

Overall Chinese students' satisfaction was the only dependent variable in this study, which was assumed to be influenced by all of the above independent variables. The questionnaire had 3 items under this construct, which were; students' overall satisfaction with their choice to study in Thailand, their willing to recommend to their friends in China, and the expense of coming to study in Thailand was worth it.

\section{DATA ANALYSIS}

After checking the precision of data entry and making codes for data analysis with the statistical analysis program, SPSS/PC for Windows, version 15.0, the following statistics were used. Descriptive statistics consisted of frequency, percentage, mean, and standard deviation that were used to report information about personal characteristics of the sample, their level of preparation, and level of satisfaction. For the hypothesis testing part, inferential statistics; multiple regression and correlation analysis, were performed to identify the relationships between all seven factors (independent variables) and the overall student satisfaction (dependent variable), and to examine which of the seven factors having the predictive power on the overall student satisfaction.

From the sample of 215 Chinese students studying in higher education institutions in Bangkok, the research findings were concluded and classified into 3 parts as follows;

- $\quad$ Part 1: Demographic data of the sample (see Table I).

The majority or $136(63.3 \%)$ were female. Most of the samples, 79 (36.7\%) students, were at the age of 22 , and the respondents' average age was 21.83 years old. Most of them came from Guangxi province, which accounted for 119 $(55.3 \%)$ students. The samples studying at Chandrakasem 
Rajabhat University were the largest group with 75 (34.9\%) samples, and bachelor's degree students, 115 (53.5\%), came to Thailand to study Thai language. The details are shown in:

- Part 2: Level of Chinese students' preparation and satisfaction toward Thai higher education

TABLE I: NUMBERS AND PERCENTAGES OF THE RESPONDENTS CLASSIFIED BY PERSONAL DEMOGRAPHY $(N=215)$

\begin{tabular}{|c|c|c|}
\hline Personal Factor & Number & Percentage \\
\hline \multicolumn{3}{|l|}{ Gender } \\
\hline female & 136 & 63.3 \\
\hline Male & 79 & 36.7 \\
\hline \multicolumn{3}{|l|}{ Age } \\
\hline 18 & 1 & 0.5 \\
\hline 19 & 2 & 0.9 \\
\hline 20 & 20 & 9.3 \\
\hline 21 & 73 & 34 \\
\hline 22 & 79 & 36.7 \\
\hline 23 & 25 & 11.6 \\
\hline 24 & 4 & 1.9 \\
\hline 25 & 2 & 0.9 \\
\hline 26 & 3 & 1.4 \\
\hline 27 & 2 & 0.9 \\
\hline 28 & 2 & 0.9 \\
\hline 29 & 2 & 0.9 \\
\hline \multicolumn{3}{|l|}{ Province } \\
\hline Guangxi & 119 & 55.3 \\
\hline Yunnan & 57 & 26.5 \\
\hline Fujian & 12 & 5.6 \\
\hline Guangdong & 11 & 5.1 \\
\hline Hunan & 4 & 1.9 \\
\hline Sichuan & 2 & 0.9 \\
\hline Shanghai & 2 & 0.9 \\
\hline Liaoning & 2 & 0.9 \\
\hline Hubei & 1 & 0.5 \\
\hline Beijing & 1 & 0.5 \\
\hline Jiangsu & 1 & 0.5 \\
\hline Guizhou & 1 & 0.5 \\
\hline Zhejiang & 1 & 0.5 \\
\hline Hebei & 1 & 0.5 \\
\hline \multicolumn{3}{|l|}{ University } \\
\hline Chandrakasem Rajabhat U. & 75 & 34.9 \\
\hline Rangsit U. & 48 & 22.3 \\
\hline Siam U. & 26 & 12.1 \\
\hline Dhonburi Rajabhat U. & 21 & 9.8 \\
\hline Suan Sunandha Rajabhat U. & 20 & 9.3 \\
\hline Bansomdejchaopraya Rajabhat U. & 19 & 8.8 \\
\hline Chulalongkorn U. & 4 & 1.9 \\
\hline Ramkhamhaeng U. & 1 & 0.5 \\
\hline Bangkok U. & 1 & 0.5 \\
\hline \multicolumn{3}{|l|}{ Field of Study } \\
\hline Thai Language & 115 & 53.5 \\
\hline International Business Mgt & 27 & 12.6 \\
\hline Business Administration & 25 & 11.6 \\
\hline Finance & 24 & 11.2 \\
\hline Tourism Management & 20 & 9.3 \\
\hline Cultural Management & 3 & 1.4 \\
\hline Mass Communication & 1 & 0.5 \\
\hline \multicolumn{3}{|l|}{ Level of Study } \\
\hline Bachelor's degree & 176 & 81.9 \\
\hline Certificate & 32 & 14.9 \\
\hline Master's degree & 7 & 3.3 \\
\hline
\end{tabular}

Regarding Chinese students' preparation before coming to study in Thailand, the level of their overall preparation was in fair level (Mean $=3.30, S D=0.730)$. In terms of Chinese students' satisfaction in connection with both educational and non-education services, the results got from the responded questionnaires found that the overall satisfaction level of the sampled students toward Thai higher education was in satisfied level (Mean $=3.51, S D=$ 0.799). Focusing on each aspect, the most satisfied factor of all six was safety, being in satisfied level (Mean $=3.62$, $S D=0.713)$. The second ranking satisfied factor was education with satisfied level (Mean $=3.52, S D=0.700)$ and the least satisfied factor was economic consideration (Mean $=2.97, S D=0.689)$, which were in the same level of neutral, as presented in Table II.

TABLE II: SUMMARY OF DESCRIPTIVE STATISTICS $(N=215)$

\begin{tabular}{lccc}
\hline \multicolumn{1}{c}{ Variables } & Mean & $\begin{array}{c}\text { Std. } \\
\text { Deviation }\end{array}$ & Meaning \\
\hline \multicolumn{1}{c}{ External Factors } & & & \\
Preparation & 3.3 & 0.730 & Fair \\
\hline \multicolumn{1}{c}{ Internal Factors } & & & \\
Safety & 3.62 & 0.713 & Satisfied \\
$\begin{array}{l}\text { Education } \\
\text { Infrastructure and administrativi } \\
\text { support }\end{array}$ & 3.52 & 0.700 & Satisfied \\
$\begin{array}{l}\text { Social and cultural support } \\
\text { Image and prestige of institutior }\end{array}$ & 3.13 & 0.744 & Neutral \\
Economic considerations & 2.97 & 0.689 & Neutral \\
\hline \multicolumn{1}{c}{ Overall Satisfaction } & 3.51 & 0.799 & Satisfied \\
\hline \hline
\end{tabular}

- Part 3: Factors influence Chinese students'satisfaction toward Thai higher education (Hypothesis testing)

For hypothesis testing, Pearson's product moment correlation was performed to identify the relationships between seven independent variables and the dependent variable for testing Hypothesis $1(H I)$. Besides, Multiple Regression was used for examining the predictive power of these seven factors on the overall student satisfaction to test Hypothesis $2(H 2)$ of the study. The two hypotheses were tested and concluded as follows;

\section{A. Correlation Analysis}

H1: All seven factors (student's preparation, education, social and cultural support, economic considerations, safety, and image and prestige of institution) will have a positive relationship with overall student satisfaction.

Table III indicated that all the seven hypothesized factors (independent variables) had the significant positive relationships with the overall Chinese students' satisfaction (dependent variable), being significant at 0.000 level. The factor having the highest positive relationship with overall student satisfaction was education $(\mathrm{r}=0.723, \mathrm{p}=0.000)$, followed by safety $(\mathrm{r}=0.686, \mathrm{p}=0.000)$, infrastructure and administrative support $(\mathrm{r}=0.671, \mathrm{p}=0.000)$, image and prestige of institution $(\mathrm{r}=0.622, \mathrm{p}=0.000)$, economic considerations $(\mathrm{r}=0.595, \mathrm{p}=0.000)$, social and cultural support $(\mathrm{r}=0.545, \mathrm{p}=0.000)$, and student's preparation $(\mathrm{r}=$ $0.483, \mathrm{p}=0.000$ ). Therefore, Hypothesis 1 was confirmed and supported by Pearson's correlation coefficient results, as shown in Table III. 
TABLE III: SUMMARY OF CORRELATIONS AMONG VARIABLES $(N=215)$

\begin{tabular}{|c|c|c|c|c|c|c|c|c|}
\hline Variables & $\overline{1} \mathbf{1}$ & 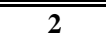 & 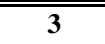 & 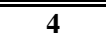 & 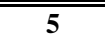 & 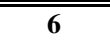 & 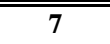 & 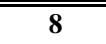 \\
\hline 1. Preparation & & $.496^{* * *}$ & $.473^{* * *}$ & $.438 * * *$ & $.431 * * *$ & $.418^{* * *}$ & $.361 * * *$ & $.483 * * *$ \\
\hline 2. Education & & & $.742 * * *$ & $.781 * * *$ & $.627 * * *$ & $.699 * * *$ & $.673 * * *$ & $.723 * * *$ \\
\hline 3. Social and Cultural Support & & & & $.726^{* * *}$ & $.588 * * *$ & $.586^{* * * *}$ & $.622^{* * *} *$ & $.545^{* * *}$ \\
\hline 4. Infrastructure and Administrative Support & & & & & $.721 * * *$ & $.719 * * *$ & $.715^{* * *}$ & $.671 * * *$ \\
\hline 5. Economic Considerations & & & & & & $.596 * * *$ & $.567 * * *$ & $.595 * * *$ \\
\hline 6. Safety & & & & & & & $.597 * * *$ & $.686^{* * * *}$ \\
\hline 7. Image and Prestige of Institution & & & & & & & & $.622 * * *$ \\
\hline
\end{tabular}

Note: Significant at $* * * p<0.001$.

TABLE IV: SUMMARY RESULTS OF MULTIPLE REgRESSION ANALYSIS AMONG VARIABLES ( $N=215)$

\begin{tabular}{|c|c|c|c|c|c|c|c|c|}
\hline Variables & & $\overline{\mathrm{B}}$ & 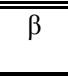 & $\overline{\mathrm{T}}$ & $\overline{\mathrm{R}}$ & $\overline{\mathrm{R}^{2}}$ & $\begin{array}{l}\mathrm{R}^{2} \\
\mathrm{adj} .\end{array}$ & Overall F \\
\hline Criterion & & & & & 0.79 & 0.62 & 0.608 & $84.117 * * *$ \\
\hline \multirow[t]{4}{*}{ Predictor: } & 1.Education & 0.39 & 0.34 & $40847 * * *$ & & & & \\
\hline & 2.Safety & 0.33 & 0.29 & $4.718 * * *$ & & & & \\
\hline & 3.Image and prestige of institution & 0.17 & 0.17 & $2.9606^{* *}$ & & & & \\
\hline & 4.Preparation & 0.14 & 0.13 & $2.647 * *$ & & & & \\
\hline
\end{tabular}

Note: Significance level: $* * p<0.01 * * * p<0.001$

\section{B. Multiple Regression Analysis}

H2: All seven factors (student's preparation, education, social and cultural support, economic considerations, safety, and image and prestige of institution) will be the significant predictors of overall student satisfaction.

From Table IV, overall student satisfaction was defined as criterion or dependent variable. After analyzing with stepwise multiple regression, the result showed that, with all seven variables, only four independent variables were shown to be the significant predictors of the overall student satisfaction; which were: satisfaction with: education, safety, image, and prestige of institution, and student's preparation, even though positive relationships among all seven factors were found (H1). Therefore, Hypothesis 2 was party confirmed. The multiple regression model with these four factors could account for $60.8 \%$ of the variance in the overall student satisfaction (Adjusted $\mathrm{R}^{2}=0.608$ ).

From these four factors. Student satisfaction with education had the highest Beta coefficient $(\beta=0.337$, $\mathrm{p}=0.000)$, followed by satisfaction with safety $(\beta=0.292$, $p=0.000)$, image and prestige of institution $(\beta=0.173$, $\mathrm{p}=0.004)$, and student's preparation $(\beta=0.131, \mathrm{p}=0.009)$. To conclude, the factor having the highest significant predictive power and positive influence on overall Chinese students' satisfaction toward Thai universities was student satisfaction with education, followed by safety, image and prestige of institution, and student's preparation, respectively. Fig. 2 summarizes the analysis results and illustrates the multiple regression model confirmed in this study.

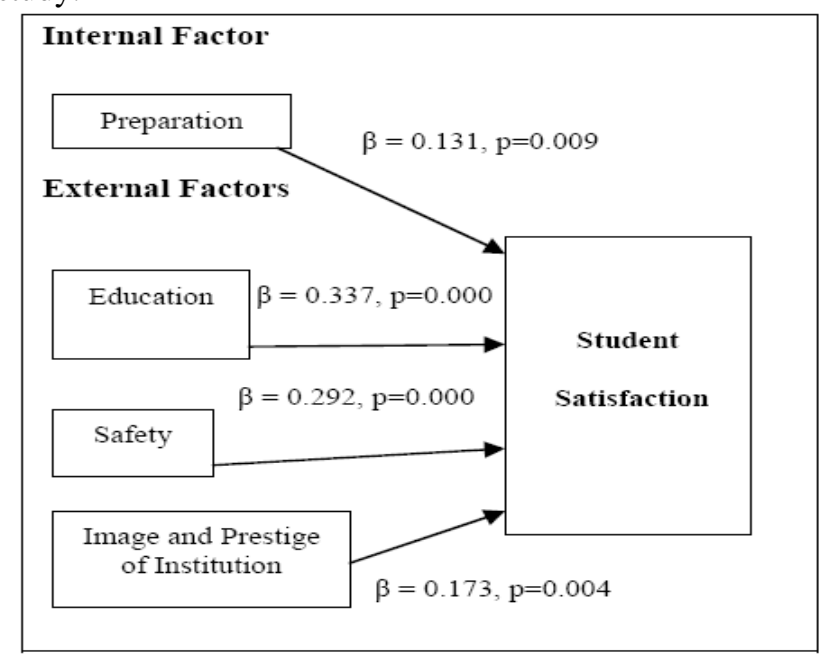

Fig. 2. Multiple regression model.

\section{DISCUSSION}

Research findings revealed that only four factors; education, safety, image and prestige of institution, and student's preparation, have significant positive influence on overall Chinese students' satisfaction toward Thai higher education.

A possible explanation for these findings; education factor, this is a direct educational issue. It is in line with the finding of [4] claimed that the importance of teaching 
quality and the role of lecturers including a suitable learning environment are perceived to be the most important variable influencing and generating student satisfaction.

In addition, the finding was in conformity with Herzberg's two-factor theory. Based on Herzberg's theory, education issue (lecturers, quality of teaching, course content, and classes) may be considered as "satisfier or motivator".

Regarding Safety and Image and prestige of institution, the result of these two significant factors (predictors) partially corroborated the previous research of [4]. From their study, they acknowledged the other important factors other than direct educational issues, which included these two factors as influential attributes towards student satisfaction. They asserted that satisfy is a major concern to international students and their families; good reputation for safety, racial tolerance, and cultural mix are also considered from a safety prospective. Their findings additionally indicated that image and prestige of institution; the university, its courses, teachers and comparative ranking with other universities are all concerned by students because high image and prestige would create better career opportunities for them. The attractive universities rely on its quality and reputation in their own country, internationally, and in the home country of the students. They also mentioned about the strength of the alumni network in the student's home country which can contribute to this construct.

Lastly, the multiple regression results indicated that preparation, regarded as internal factor, had significant predictive power and positive influence on Chinese students' satisfaction. This outcome fully supported and confirmed to the prior study of [9]. Their findings suggested that Chinese students' preparation before studying abroad is essential for the students to do well in the program and the students who felt they were better prepared for study abroad showed higher satisfaction. Thus, the better prepared students feel, the higher the satisfaction level. Therefore, preparation is the significant factor in getting student satisfaction out of the study abroad program.

\section{RECOMMENDATION}

Knowing what influences student satisfaction is the first step in improving it. In reference to the analysis findings, these influential factors were: education, safety, image and prestige of institution, and preparation. Having an insight on Chinese students' satisfaction with their study experience in Thailand, Thai universities should pay more attention to these aspects and adapt to the changing needs of their customers. As Chinese students are the main potential and prospective customers among all international students studying in Thailand, the ability of Thai higher education institutions to pinpoint what they want is a crucial factor affecting institutional and managerial success. The results from the study could facilitate and support Thai education provides to improve their existing planning and programs' management including their future course establishment. Furthermore, these might help government sector considering and appraising their international higher education policies and implementation.

In accordance with the results of this study, to indicate areas for improvements, there were four factors having neutral satisfaction level (infrastructure and administrative support, social and cultural support, image and prestige of institution, and economic consideration). Although these factors were not in unsatisfied level but Thai higher education institutions should attempt to improve it to gain more student satisfaction, which lastly results to valuable source of powerful word of mouth referrals. Moreover, they should have customer-oriented attitude in order to be able to support and satisfy their Chinese students.

For the government sector, they should assist higher education institutions in developing their academic and professional capacities to meet international standards. Thai higher education system should address and act in response with the emerging needs and demands of international students with the goals to enhance Thailand competitiveness in education business. The government should strengthen, develop, and promote policies on quality assurance in both public and private higher education institution in order to provide quality higher education. To provide education to gain more international recognition, it is essential that ministry of education needs to make great efforts on putting more advertisements and promotions for Thai higher education in China and elsewhere in order to increase more international awareness and promote Thai higher education to be one of the interesting study destination in Asia. For example, participating or organizing international education exhibitions or road shows.

\section{LIMITATION OF THE STUDY}

This research faced several limitations which must be considered when interpreting the research findings. Firstly the survey of this study had to be conducted faster than the originally planned time frame due to the time constraint from student semester ending, most of Chinese students went back home for their vacation, during the data collection period. Consequently, the researchers had to apply $7 \%$ sampling error. Therefore, the result of this study may not be generalized to represent the whole Chinese students studying in Thailand. Secondly, the researcher experienced multicollinearity problem in multiple regression analysis because the independent variables in this study were correlated with each other, and some had rather high degree of correlations. Therefore, it may create unstable regression coefficients. The third limitation is that some satisfaction items under each factor might be overlapped or not clearly divided. Moreover, the independent variables in the model might not cover all important satisfaction determinants. Lastly, most of the respondents avoided giving any comments and suggestions of the open-ended question which is the last part of the questionnaire. Therefore, it was difficult to get in-depth information of what their preferences and needs.

\section{FUTURE RESEARCH}

There are many issues worth exploring further. Due to the 
fact that this study covered only Chinese students studying in Bangkok, in order to expand and improve the scope of knowledge in this related topic, future research may extend a scope of study by conducting in other provinces for the benefit of diverse information. In addition, further research should consider the ideal time to assess student satisfaction and also lengthen data collection period.

Because of the multicollinearity problem faced in this study, the researcher suggested future research to thoroughly review independent variables used in their study, and remove any independent variables that are highly correlated with others in a multiple regression equation. Another way is to combine correlated variables by using factor analysis so as to decrease number of variables. Additionally, one more alternative is to increase sample size in order to reduce the impact of multicollinearity.

Finally, according to the output of the study, the adjusted $R^{2}(0.608=60.8 \%)$ indicated that some important factors explaining student satisfaction were still missing. Therefore, further research should address any missing and significant impact factors by using focus group method which might help indicating other dimensions of satisfaction that were not captured during this study. Also, this study applied quantitative research using questionnaires as a tool to collect the primary data. Study in the future could be conducted by using an in-depth interview, a qualitative research, in order to get more specific data from respondents.

\section{REFERENCES}

[1] Bohm, Davis, Meares and Pearce, "Global student mobility 2025, forecast of demand for international education," IDP Education Australia, Sydney, pp. 2-6, September 2002.

[2] Office of the Higher Education Commission. (2009). Bureau of International Cooperation Strategy. Ministry of Education. International Programmes in Higher Education Institutions. [Online]. Available: http://inter.mua.go.th/main2/list.php?id=fa02
[3] K. M. Elliott and D. Shin, "Student satisfaction: an alternative approach to assessing the important concept," Journal of Higher Education Policy and Management, vol. 24, no. 2, pp. 197-209, 2002.

[4] R. Arambewela and J. Hall, "An empirical model of international student satisfaction," Asia Pacific Journal of Marketing and Logistics, vol. 21, no. 4, pp. 555-569, 2009

[5] P. Kotler and K. L. Keller, Marketing Management, 13 th ed. United States: Pearson Prentice Hall.

[6] O. W. DeShield, A. Kara, and E. Kaynak, "Determinants of business student satisfaction and retention in higher education: applying herzberg's two-factor theory," International Journal of Education Management, vol. 10, no. 2, pp. 128-139, 2005.

[7] S. M. Keareney and C. E. Young, "The student satisfaction and retention model(SSRM)," Working Paper, University of Colorado, Denver, CO, 1997

[8] A. Parasuraman, V. Zeithaml, and L. Berry, "A conceptual model of service quality and its implication for future research," Journal of Marketing, vol. 49, pp. 41-50, 1985.

[9] Q. Wang, R. Taplin, and A. M. Brown, "Chinese students' satisfaction of the study abroad experience," International Journal of Education Management, vol. 25, no. 3, pp. 265-277, 2011.

[10] T. Yamane, Statistics, an Introductory Analysis, 2 nd ed. New York, Harper and Row, 1967.

Paweena Songsathaphorn graduated as a bachelor of laws from Chulalongkorn University. After her graduation, she continued her postgraduate study at Les Roches, School of Hotel Management, Switzerland, for Postgraduate Certificate and lastly in 2012, she received her Master's degree in International Business Management from Chulalongkorn Business School, Chulalongkorn University.

Chenin Chen is a visiting professor at Chulalongkorn Business School, Chulalonglorn University. He received his D.B.A. from United States International University, California, USA. He is the managing director of Rayong Wire Industries Public Company Limited, and board director of Capital Engineering Network Public Company Limited and Ua Withya Public Company Limited, both are listed companies in Thai Stock Exchange Market.

Athapol Ruangkanjanases is a faculty member at Department of Commerce, Chulalongkorn Business School, Chulalonglorn University. He received his Ph.D. from Illinois Institute of Technology, USA. Before joining Chulalongkorn University, he taught at School of Management, Marist College, New York, USA 